\title{
A luta das comunidades indígenas Sawhoyamaxa e Apika'y: a Anistia Internacional e a questão das Terras Tradicionais
}

The struggle of the indigenous Sawhoyama and Apika'y: Amnesty International and the question of traditional lands

\author{
Carla Cristina Vreche ${ }^{1}$ \\ Marcos Antônio da Silva²
}

RESUMO: $O$ presente artigo objetiva analisar a prática do ativismo transnacional na luta pelo reconhecimento de terras indígenas. Nesse sentido, discute o reconhecimento dos direitos dessas comunidades sob a ótica do direito às suas terras ancestrais. Para tanto são apresentados os casos das comunidades Sawhoyamaxa e Apika'y, ambas objeto de campanha da ONG Anistia Internacional.

Palavras-chave: Ativismo Transnacional; Comunidade Sawhoyamaxa; Comunidade Apika'y.

ABSTRACT: This article aims to analyze the practice of transnational activism in the struggle for recognition of indigenous lands. In this sense, it discusses the recognition of the rights of these communities from the perspective of the right to their ancestral lands. Therefore presents the cases of the Sawhoyamaxa and Apika'y communities, both campaign objects of NGO Amnesty International.

KEY-WORDS: Transnational activism; Sawhoyamaxa; Apika'y.

\section{INTRODUÇÃO}

O problema da violação de direitos de comunidades indígenas (ou tradicionais) é algo intrínseco a vários espaços e países e, sobretudo, foi e é um elemento constante na história da América Latina. Tema cotidiano da vida desses povos, as dificuldades encontradas vão desde a fragilidade na representação de suas demandas à falta de interesse dos respectivos Estados, os quais dificultam o acesso e a garantia integral de seus direitos. O problema enfrentado é muitas vezes o do próprio reconhecimento desses indivíduos, seja em sua singularidade e, sobretudo, em sua coletividade.

Em busca de uma melhor e nova forma de articulação, que ultrapasse esse reconhecimento estatal bloqueado, essas comunidades e indivíduos, passaram a se unir

\footnotetext{
${ }^{1}$ Mestra em Sociologia pela Universidade Federal da Grande Dourados (UFGD), Dourados, Brasil.

2 Doutor em Integração da América Latina pela USP. Professor de Ciência Política do curso de Ciências Sociais da Universidade Federal da Grande Dourados (UFGD) e membro do Laboratório Interdisciplinar de Estudos sobre América Latina (LIAL/UFGD), Dourados, Brasil.
} 
a outros atores, dentre os quais as Organizações Não-Governamentais (ONGs). Como o cenário atual é caracterizado não somente pelo fortalecimento dos instrumentos e documentos internacionais de direitos humanos, mas também pelo próprio fortalecimento do sistema das Nações Unidas, a articulação através do ativismo transnacional destaca-se entre as alternativas. Busca-se, deste modo, pressionar os respectivos Estados através da abertura e elevação de suas pautas específicas ao debate internacional, gerando pressão política internacional sobre pautas que em suas raízes são essencialmente nacionais. Cria-se o shaming internacional que pressiona o comportamento nacional estatal (BAEHR, 2009) ${ }^{3}$.

Nesse sentido, este trabalho se propõe a apresentar e analisar, de forma comparativa, o ativismo transnacional desenvolvido pelas comunidades indígenas Apika'y (Brasil) e Sawhoyamaxa (Paraguai), que, por meio dessa ferramenta, buscam contornar a pressão e a soberania exercidas por seus respectivos Estados e também pautar e agir em prol de seu reconhecimento e de seus direitos coletivos. Especificamente, será destacada a interlocução e atuação da ONG Anistia Internacional na organização e construção de campanhas que potencializam o alcance internacional dessas pautas, especialmente aquela ligada ao direito às terras tradicionais.

Para tanto, o trabalho se inicia a partir da discussão em torno da prática do ativismo transnacional. Em seguida, será discutido o reconhecimento das comunidades indígenas no Brasil e no Paraguai, a partir de documentos nacionais e internacionais, relacionando-as segundo a perspectiva da luta pelo reconhecimento de suas terras ancestrais. Na terceira seção, será apresentada a história dessas comunidades e por fim, será apontada a atuação e as campanhas desenvolvidas pela Anistia Internacional em ambos os casos.

\section{1) O ATIVISMO TRANSNACIONAL}

0 término das tragédias que marcaram a Segunda Guerra Mundial proporcionou à humanidade o estreitamento dos laços e das relações entre os Estados, assim como o avanço da modernização tecnológica e dos meios de comunicação. Em conjunto esses

\footnotetext{
3 O shaming apresentado por Baehr (2009) está relacionado à ideia de criar um constrangimento aos Estados, na esfera internacional, através da demonstração e evidenciação internacional de que estes têm cometido, internamente, graves violações de direitos humanos, por exemplo. Ou seja, de que algum modo estes Estados estão violando regras internacionalmente acordadas e ratificadas por eles mesmos. 0 que se espera desse processo é o que Estado sinta-se constrangido, através da pressão externa que lhe é imposta, e este altere seu comportamento internamente.
} 
elementos, relacionados também ao desenvolvimento dos transportes, geraram grandes e importantes rupturas sociais e políticas (MÖHRING, 2009; VILLA, 1999).

Nesse sentido, esse cenário também foi marcado pelo surgimento do sistema de Estados e pelas relações estabelecidas entre esses atores através da criação da ONU em 1945, bem como por meio dos tratados e outras organizações internacionais de caráter global ou regional. Além disso, é possível destacar a ampliação do leque de atores internacionais que ganham evidência, para além dos Estados, no processo de tomada de decisões, como as ONGs (AHMED e POTTER, 2006).

Segundo Villa (1999), diante deste novo contexto, as ONGs de direitos humanos passaram a atuar de maneira a buscar quebrar o monopólio exercido pelo Estado nas relações internacionais. Em conjunto, portanto, o pluralismo político ocidental e a rápida modernização, segundo o autor acima citado, "criou[ram] uma maior organização societal" (VILLA, 1999), permitindo uma maior participação e atuação das ONGs no âmbito internacional.

A intensificação da atuação destas organizações foi responsável por permitir o alcance internacional de certos problemas e demandas que antes se concentravam e se limitavam ao âmbito nacional. Esse movimento, que permitiu a elevação de problemáticas para além das esferas e fronteiras nacionais, abriu a porta à prática do ativismo transnacional. Ou seja, pode-se identificar essa prática como mobilizações criadas por grupos, ONGs ou segmentos da sociedade civil organizada de diversos países que juntos conseguem criar e articular um espaço de discussão sobre assuntos nacionais na esfera internacional (KECK e SIKKINI, 1998).

Como aponta Santos (2010), tais ações são importantes porque promovem alianças entre grupos e pautas sensíveis, como as de sociedades indígenas que decidem atuar internacionalmente e ONGs que atuam diretamente em prol do processo de globalização das lutas sociais, pois

A ligação de ONGs a movimentos de base assume especial importância na mobilização de formas de conhecimento que permitem a formulação de leis e de políticas alternativas de base popular, a partir de diferentes fontes e recursos. Deste modo, ONGs e movimentos sociais aparecem como mediadores cruciais entre diferentes formas de direito e entre comunidades locais, o Estado nacional e as organizações internacionais (SANTOS, 2010, 57). 
Assim, a mobilização criada junto às ONGs internacionais possibilita a transnacionalização de pautas sociais nacionais que, antes de se verem totalmente bloqueadas e pressionadas, buscam contornar a resistência estatal, lançando tais demandas no âmbito internacional.

É o reconhecimento e o fato dos Estados estarem envoltos no sistema internacional de Estados, o qual estabelece importantes e diferentes formas de interações estatais, que leva os mesmos a reagirem quando tomam conhecimento da pauta em discussão, a qual é posta por agentes da sociedade civil. Assim, a prática do ativismo transnacional necessita de estudos aprofundados e, embora pouco explorada na literatura (KECK e SIKKINK, 1998; Della PORTA e TARROW, 2004; SIKKINK, 2011), permite-nos compreender o atual quadro das relações internacionais e da interação entre os diferentes atores, como nos casos que aqui serão analisados.

Segundo Keck e Sikkink (1998) as redes de ativismo transnacional correspondem aos resultados das interações entre ONGs, Estados e organizações internacionais, que por diferentes motivos passam a fazer parte de uma rede promovendo uma causa, norma ou ideia. Consideradas importantes componentes na alteração da política mundial, essas redes se caracterizam pela organização, influência e pressão das ONGs, que buscam alterar o comportamento de Estados e de organizações internacionais. Neste caso, as ONGs são os atores responsáveis por informar, organizar discussões e promover novas ideias, além de poderem participar como empreendedoras da norma ${ }^{4}$.

Baseando-se em princípios e valores comuns, os membros que compõem a rede se unem e buscam alterar padrões através do constante compartilhamento de informações que as redes as disponibiliza. Neste aspecto, a mídia exerce importante papel ao facilitar o compartilhamento dessas informações e por chamar a atenção de outros atores às pautas em discussão. Em resumo, através de suas atividades, seu lobby e campanhas de pressão, as ONGs buscam alterar o padrão de comportamento de outros atores.

\footnotetext{
${ }^{4}$ Empreendedores normativos são aqueles atores decisivos para a emergência de uma norma. São os responsáveis por chamarem a atenção a determinadas questões ou mesmo por criarem estas. Para que haja resultados buscam dramatizar a situação correspondente à norma que desejam empreender (FINNEMORE e SIKKINK, 1998, 16).
} 
No caso da luta indígena, a organização de pautas em torno do ativismo transnacional surge como um reforço ao avanço constitucional verificado em alguns países. Aos indígenas não foram garantidos apenas direitos nacionalmente reconhecidos, mas também há um conjunto de tratados e documentos internacionais que, assinados pelos Estados, apesar de marginalizados ou mesmo ignorados, passaram a pautar e a permitir a prática do ativismo transnacional.

\section{2) OS DIREITOS DOS POVOS INDÍGENAS EM QUESTÃO: RECONHECIMENTO OU SUBALTERNIDADE?}

Os Estados latino-americanos apresentam uma história geral bastante comum, apesar de algumas especificidades, em relação ao tratamento destinado às suas populações indígenas, no passado e no presente, pois como demonstra Linera,

A sociedade oficial significa, para o indígena, o mesmo que a morte representa para os aferrados à vida: ambos os casos são entendidos como negação de qualquer existência possível. Assim como a vida é a fuga permanente da morte, nos países latino-americanos o "social" é a perpétua prevenção do "índio" no ordenamento público; o progresso é o extermínio do indígena ou sua domesticação civilizatória (...) (LINERA, 2010, 153).

Desta forma, desde o período colonial, passando por seus respectivos processos de independência, segundo Santos (2010), o tratamento das sociedades tradicionais aqui presentes foi bastante similar, pautada pela incorporação forçada e subalterna dos indígenas as suas respectivas sociedades:

A política colonialista na América pautou-se pela subjugação e integração dos povos que ia encontrando. A subjugação cultural e econômica consistia em promover uma integração forçada, religiosa e econômica. Ou isso, ou a destruição. A política variou de acordo com a violência ou ambição de seu executor (SANTOS, 2010, 77).

Foram desconsiderados, desde o início, os direitos coletivos, tradicionais desses povos em que o senso de comunidade é fundamental, isso devido, sobretudo, à inserção dos direitos individuais como categoria básica para o exercício de direitos. A história da formação e consolidação dos Estados latino-americanos foi, assim, marcada pela exclusão e marginalização das sociedades tradicionais e seus referenciais, pois:

As relações destes Estados constituídos no começo do século XIX com os povos originais de seus territórios também são similares. Eles herdaram um passado colonial comum, usaram os povos nas guerras de independência, acreditaram que poderiam integrá-los como cidadãos garantindo-lhes direitos individuais, inclusive de propriedade da terra, desconsiderando seus usos, costumes, tradições, línguas, crenças e territorialidade; quando em conflito, enfrentaramnos em guerras sórdidas ou por repressão direta. Os direitos dos povos 
indígenas, por serem coletivos, foram omitidos das legislações escritas (SANTOS, 2010, 92).

Este processo criou pressão sobre a cultura, costumes e tradições, assim como sobre a própria ideia de territorialidade apresentada por estes povos, que sob a ótica dos Estados é bastante diferente daquela que apresenta Little (2002), pois se baseia numa concepção ampla, fundamentada na cosmografia. Segundo este, o conceito de territorialidade e, portanto, a terra, seria produto histórico de processos sociais e políticos que apresentam uma multiplicidade de expressões:

\section{A expressão dessa territorialidade, então, não reside na figura de leis ou título, mas se mantém viva nos bastidores da memória coletiva que incorpora dimensões simbólicas e identitárias na relação do grupo com sua área, o que dá profundidade e consistência temporal ao território (LITTLE, 1994, 11).}

Ou seja, a concepção da terra para estas comunidades seria muito diferente da concepção de propriedade privada ou mesmo do conceito de propriedade estatal. Aqui a terra está envolta de um conjunto de processos históricos, sociais e, principalmente, imersa em um universo de símbolos e significados os quais não podemos identificar se seguirmos a lógica do Estado Moderno Ocidental ou da modernização capitalista.

Além disto, a importância e a relevância que assume o debate sobre a terra na luta dessas comunidades, especificamente nos casos aqui trabalhados, mas que se refere a todas as comunidades tradicionais da região, diz respeito ao fato de que a garantia às suas terras ancestrais é a essência da garantia de seus direitos. Ou seja, é a partir deste que as comunidades verificariam a garantia de todos seus outros direitos, já que estes estão extremamente ligados à Terra Mãe, como afirma Araújo (2006):

0 direito à terra está, sem sombra de dúvidas, na essência dos direitos dos povos indígenas. Da sua garantia dependem todos os demais direitos e a própria continuidade e reprodução cultural desses povos. Por isso mesmo, em torno da sua aplicação ocorrem os maiores conflitos e aí se opera toda uma usina de fabricação de preconceitos que procuram deslegitimá-lo e desqualifica-lo (ARAÚJO, 2006, 49).

Tal situação, presente em toda história latino-americana foi realçada durante os regimes militares na região, principalmente na América do Sul e Central, que reprimiram com bastante intensidade os indígenas. Neste sentido, segundo Bovo (2002), os povos 
indígenas, assim como os campesinos, foram no Brasil, por exemplo, os que mais sofreram violações de seus direitos durante o período ditatorial pelo qual passou o país 5 .

Com a redemocratização, ao longo da década de 80 , pode-se destacar que a questão indígena ressurge como um dos componentes fundamentais para o desenvolvimento democrático e, apesar das diferenças de intensidade, tal questão, impulsionada pelos movimentos sociais e pelos tratados internacionais, adentra a arena política, principalmente nos países em que tal população era majoritária, como no caso andino, embora ainda esteja longe de ser definitivamente solucionada (LINERA, 2010).

Neste sentido, tais povos adentraram a arena política, inserindo nos textos constitucionais seus direitos e, mais recentemente, elegendo representantes e inserindo suas concepções nas disputas políticas regionais (SANTOS, 2010).

Mesmo no caso brasileiro, pode-se considerar, segundo Little que

(...) os povos indígenas ganharam força política mediante um processo de organização interna de suas sociedades, alianças regionais e nacionais, entre distintas sociedades indígenas, e até presença no Congresso Nacional. Essas forças exerceram um papel importante no reconhecimento e ampliação de seus direitos na Constituição de 1998 (LITTLE, 2004, 14).

Essas constituições, diferente do que ocorrera na história constitucional desses países, passaram a reconhecer, em graus diferenciados, os direitos dessas comunidades tradicionais.

Em tese, as sociedades tradicionais passaram a ter seus direitos legitimados pelos seus respectivos Estados nacionais; um direito que na teoria seria à diferença e não assimilacionista. Entretanto, como destacado por Santos (2010), o reconhecimento desses direitos, de caráter coletivo, encontra dificuldade em se realizar visto que o marco jurídico no qual estamos inseridos torna difícil sua efetivação ou proteção.

A Constituição do Brasil (1988), por exemplo, apresenta importantes avanços em todo o seu texto, sendo que os Capítulos VII (Da Ordem Social) e VIII (Dos Índios) são especialmente importantes ao afirmarem que

\footnotetext{
${ }^{5}$ Reconhecemos aqui, portanto, a importância do trabalho desenvolvido pela Comissão Nacional da Verdade e a sua Comissão específica para casos envolvendo a violação de direitos de comunidades indígenas.
} 
Art. 231. São reconhecidos aos índios sua organização social, costumes, línguas, crenças e tradições, e os direitos originários sobre as terras que tradicionalmente ocupam, competindo à união demarcá-las, proteger e fazer respeitar todos os seus bens.

$\S 1$ 1o São terras tradicionalmente ocupadas pelos índios as por eles habitadas em caráter permanente, as utilizadas para suas atividades produtivas, as imprescindíveis à preservação dos recursos ambientais necessários a seu bemestar e as necessárias a sua reprodução física e cultural, segundo seus usos, costumes e tradições.

$\S 2^{\circ}$ - As terras tradicionalmente ocupadas pelos índios destinam-se a sua posse permanente, cabendo-lhes o usufruto exclusivo das riquezas do solo, dos rios e dos lagos nelas existentes.

$\S 3^{\text {o }}$ - 0 aproveitamento dos recursos hídricos, incluídos os potenciais energéticos, a pesquisa e a lavra das riquezas minerais em terras indígenas só podem ser efetivados com autorização do Congresso Nacional, ouvidas as comunidades afetadas, ficando-lhes assegurada participação nos resultados da lavra, na forma da lei.

$\S 4^{0}$ - As terras de que trata este artigo são inalienáveis e indisponíveis, e os direitos sobre elas, imprescritíveis.

§ 5o - É vedada a remoção dos grupos indígenas de suas terras, salvo, "ad referendum" do Congresso Nacional, em caso de catástrofe ou epidemia que ponha em risco sua população, ou no interesse da soberania do País, após deliberação do Congresso Nacional, garantido, em qualquer hipótese, o retorno imediato logo que cesse o risco.

$\S$ 6ํ- São nulos e extintos, não produzindo efeitos jurídicos, os atos que tenham por objeto a ocupação, o domínio e a posse das terras a que se refere este artigo, ou a exploração das riquezas naturais do solo, dos rios e dos lagos nelas existentes, ressalvado relevante interesse público da União, segundo o que dispuser lei complementar, não gerando a nulidade e a extinção direito a indenização ou a ações contra a União, salvo, na forma da lei, quanto às benfeitorias derivadas da ocupação de boa fé.

$\S 7^{\text {o }}$ - Não se aplica às terras indígenas o disposto no art. $174, \S 3^{\mathrm{o}}$ e $\S 4^{\mathrm{o}}$. (CONSTITUIÇÃO FEDERAL DA REPÚBLICA FEDERATIVA DO BRASIL, 1988).

Já a Constituição paraguaia, de 1992, além do reconhecimento de uma ampla gama de direitos nos artigos 62 ao 67, reconhece a importância do idioma ao apontar que

Art. 140. El Paraguay es un país pluricultural y bilingüe.

Son idiomas oficiales el castellano y el guaraní. La ley establecerá las modalidades de utilización de uno y otro.

Las lenguas indígenas, así como las de otras minorías, forman parte del patrimonio cultural de la Nación. (CONSTITUICIÓN DE LA REPÚBLICA DE PARAGUAI, 1992) ${ }^{6}$.

${ }^{6} 0$ processo de colonização paraguaio é considerado diferenciado por Santos (2010). Segundo este autor, o Paraguai foi uma exceção. Entretanto, todo esse processo é revertido após a Guerra do Paraguai durante o século XIX. "Fracia promoveu junto com os indígenas uma verdadeira independência, expulsando os proprietários de terra e os representantes dos interesses espanhóis e ingleses. Com a força do trabalho livre e com uma política de impedir a acumulação capitalista originária e predatória, industrializou o país, garantiu excelente qualidade de vida ao povo, alfabetizado, bem nutrido e profundamente nacionalista. 
Apesar desses e outros avanços constitucionais, há ainda um longo caminho a ser percorrido para que tais direitos e as comunidades possam ser de fato respeitados. Ou seja, a legitimidade de tais direitos não conduz necessariamente à sua efetivação. Há entre esses dois elementos o descaso político, o persistente preconceito e desconhecimento da sociedade e, ainda, o avanço das fronteiras agrícolas e o extrativismo nas regiões. Dentre os maiores problemas enfrentados por estas comunidades, como mencionado acima, está o direito à terra, já que este entra em choque diretamente com o atual modo de produção e seu incessante desejo por lucro.

Para além das garantias constitucionais enfatizados anteriormente, o contexto que emergiu após a Guerra Fria impulsionou o surgimento de um conjunto de documentos e tratados que influenciavam e influenciam, ainda hoje, a garantia de direitos das comunidades indígenas espalhadas pelo mundo.

Entre os diversos documentos estão a Convenção 169 da OIT, de 1989; a Declaração da ONU sobre o Direito dos Povos Indígenas, de 2007; e a Declaração da Rede de Mulheres Indígenas sobre Biodiversidade (RMIB), de 2008. Além destes, novos encontros e debates no âmbito das Nações Unidas passaram a promover discussões sobre as condições enfrentadas por essas sociedades, reforçando um posicionamento mais assertivo por parte dos Estados, como ocorrido na II Conferência Mundial sobre o Meio Ambiente, Rio 92.

Considerando o cenário latino-americano apresentado anteriormente, apesar das especificidades nacionais, pode-se destacar que existem diversos obstáculos comuns na efetivação e realização plena dos direitos de comunidades indígenas. Sendo assim, o que devem fazer, então, essas comunidades para que a plenitude de seus direitos seja reconhecida? Sem dúvida, o apelo à comunidade internacional defendida por Segato (2006), baseando-se em tratados ratificados pelos Estados internacionalmente, assim como na exposição da situação enfrentada nacionalmente e da publicidade de seus

Esta experiência de liberdade durou quatro décadas. Inconformada com o exemplo paraguaio, a Inglaterra incentivou e subvencionou a Argentina, o Brasil e o Uruguai a promover uma guerra de destruição, até que tombasse o último homem paraguaio. Hoje o Paraguai, destruído no século passado, guarda como marca da experiência libertária o fato de todos os paraguaios usarem o guarani como língua de comunicação familiar" (SANTOS, 2010, 76). 
casos, dos seus direitos constitucionalmente garantidos, constitui-se em uma estratégia importante, senão fundamental, para a superação de seus problemas.

Sendo assim, a seguir, discutiremos dois casos selecionados para demonstrarmos o alcance e os limites de tal estratégia, relacionada à atuação destas comunidades com a ONG Anistia Internacional.

\section{3) AS COMUNIDADES SAWHOYAMAXA (PARAGUAI) E APIKA'Y (BRASIL): SITUAÇÃO E DEMANDAS}

Os casos escolhidos para este trabalho são os das comunidades indígenas Apika'y (Brasil) e Sawhoyamaxa (Paraguai). Essa escolha se baseou em três fatores: a proximidade dos territórios; a história comum de luta por suas terras ancestrais e a atuação da ONG Anistia em ambos os casos. O caso da comunidade Sawhoyamaxa será utilizado ainda como modelo de organização e atuação para o caso brasileiro, visto que essa comunidade conseguiu o reconhecimento de suas terras depois de uma longa e intensa luta.

\section{1) A Comunidade Sawhoyamaxa}

A luta pelo reconhecimento das terras ancestrais da comunidade Sawhoyamaxa, que pertence ao Povo Enxet Sur, se inicia oficialmente em 1950. Porém, os fatos históricos que resultam nesse processo se desenvolvem anos antes. Depois da Guerra do Chaco $^{7}$ (1933-1936), a região foi submetida a um processo de venda a especuladores estrangeiros, submetendo a comunidade à alienação de suas terras e ao trabalho forçado. 0 produto imediato desse processo foi, portanto, a perda das terras ancestrais e a veloz e intensa deterioração socioeconômica dessas sociedades, nas quais os indivíduos foram forçados a negar suas estruturas sociais baseadas na economia de subsistência, segundo o relatório da Anistia Internacional Paraguai (2009).

A situação a que ficaram expostas as comunidades que viviam no Chaco, e nelas a comunidade Sawhoyamaxa, não se diferencia muito das de outras sociedades indígenas. A exploração da sua força de trabalho, assim como a plena ausência de

\footnotetext{
${ }^{7}$ A Guerra do Chaco foi um conflito envolvendo Bolívia e Paraguai pela posse da área do Chaco. Segundo Bandeira (1998), esta guerra envolvia interesses econômicos e, sobretudo, para o Paraguai, motivos estratégicos. Para a Bolívia a posse do Chaco resultaria em acesso à bacia platina e, portanto, em melhor saída para o escoamento do seu petróleo.
} 
serviços públicos básicos (como saúde, educação e habitação) garantidos e fornecidos a essas comunidades, foi e continua sendo bastante expressiva.

Diante do extenso histórico de intensas violações dos seus direitos e da inalterável indisposição do Estado paraguaio de promover qualquer mudança positiva neste cenário, em 1991 a Comunidade Sawhoyamaxa iniciou um processo que exigia a restituição de suas terras. Dispersos desde então, os membros da comunidade se uniram no assentamento "Santa Elisa", localizado à beira da rodovia Concepcion-Pozo Colorado e à frente da propriedade que requeriam por corresponder ao seu espaço ancestral. Inicialmente, não obtiveram qualquer tipo de resposta por parte do governo paraguaio ${ }^{8}$.

No entanto, em 19989, a comunidade Sawhoyamaxa conseguiu da Comissão Interamericana de Direitos Humanos um documento e declarações que alegavam que o Estado não havia garantido seus direitos, acentuando seu estado de vulnerabilidade socioeconômica. Solicitavam ainda que o governo paraguaio respondesse tal demanda, o que foi novamente ignorado pelo Estado.

Finalmente, em 200610, a Corte Interamericana de Direitos Humanos apresentou um parecer decisivo reconhecendo que esta comunidade havia sofrido um intenso processo de violação de seus direitos. Neste documento, igualmente reconhecia seu direito à vida, à propriedade e à proteção judicial. De grande importância foi, sobretudo, o reconhecimento e pressão, ordenando a restituição das suas terras ancestrais usurpadas e a condenação do Estado Paraguaio. Proferida em 2006, o cumprimento da sentença ficou prevista para o período de no máximo três anos.

\section{2) A Comunidade Apika'y}

Entre os casos emblemáticos envolvendo comunidades indígenas e a defesa de seus direitos no Brasil, estão os Guarani-Kaiowá da comunidade Apika'y, localizada na cidade Dourados no estado de Mato Grosso do Sul. Essa comunidade também possui um histórico de ameaça e expulsão de suas terras tradicionais, onde reconhecem a

\footnotetext{
8 Á esta época o presidente paraguaio era o militar Andrés Rodríguez Pedotti, responsável pelo golpe de Estado que retirou Strossner do poder.

${ }^{9}$ Em 1998, a presidência do Paraguai estava com Raúl Cubas Grau.

10 Em 2006, o presidente do Paraguai era Nicanor Duarte Frutos.
} 
existência do tekohá11, pelo avanço das fronteiras agrícolas representadas, sobretudo, pelas plantações de commodities agrícolas, como soja e cana-de-açúcar, das quais o estado é um importante exportador. Segundo Santos (2010),

O povo guarani tradicionalmente manteve seu território compartilhado com outros povos, conseguindo viver em relativa harmonia. Grandes viajantes, buscavam a terra sem males que sabiam estar a leste. A política oficial do Governo brasileiro em relação a eles foi de total omissão, por isso mesmo são os grandes invisíveis. (...) No Mato Grosso do Sul, suas terras foram ocupadas e destinadas a imigrantes brancos no início do século, em programas de desenvolvimento. (SANTOS, 2010, 83) [grifo nosso]

A luta dos Guarani-Kaiowá, é marcada pela reinvindicação e mobilização ao redor da questão da demarcação de suas terras. A comunidade Apika'y, integrada por 15 famílias, em 1990, foi expulsa de suas terras pela ação do agronegócio. Desde então, essas famílias passaram a viver em acampamentos de lonas pretas, assim como outras comunidades ao redor do Brasil. A vida na beira da estrada, em condições precárias, como a falta de condições básicas de sobrevivência, completa-se com a constante ameaça à vida dessas famílias (PITSS, 2012). Em 2009, por exemplo, sofreram um ataque que contava com 10 homens armados que diziam que os membros da comunidade deveriam deixar o acampamento. Desse ataque resultaram dois indígenas feridos, um homem e uma mulher (ANISTIA INTERNACIONAL, 2010). Após anos de descaso governamental, confinados a pequenos pedaços de terras, a comunidade deveria ter tido em 2010, suas terras demarcadas pelo governo federal, situação que, entretanto, não se concretizou. Segunda consta no Relatório produzido pela Anistia Internacional, em 2007 o Ministério Público Federal no Mato Grosso do Sul, firmou um contrato extrajudicial, o TAC (Termo de Ajustamento de Conduta) ${ }^{12}$, que deveria regulamentar 36 terras indígenas até abril de 2010. Entretanto o processo não se concretizou, pois, foram protocolados reiterados recursos pelo governo do estado, apoiado pelo importante e forte lobby de fazendeiros da região.

\footnotetext{
11 "Seu território, o solo que se pisa, é um tekoha, o lugar físico, o espaço geográfico onde os Guarani são o que são, onde se movem e onde existem." (AZEVEDO et al, 2008,10)

12 O TAC (Termo de Ajustamento e Conduta) partia de um compromisso assumido por organizações indigenistas, como a FUNAI (Fundação Nacional do Índio), junto ao Ministério da Justiça, Mistério Público Federal e 23 lideranças indígenas, e exigia o restabelecimento de 36 áreas reconhecidas como terras ancestrais.
} 
No que diz respeito à legislação brasileira, dois significativos instrumentos a serem votados podem vir a prejudicar o processo de demarcação e reconhecimento de terras indígenas pelo Estado, processo que já avança com muita dificuldade. 0 primeiro, relacionado à Portaria 303, permite que sejam revistas as demarcações de terras indígenas já realizadas. 0 outro é a Proposta de Emenda Constitucional (PEC) 215 de 2000, que transfere a autoridade de demarcação de terras indígenas da FUNAI e do poder executivo para o poder legislativo, o que dificultaria, ainda mais, o andamento de tais ações.

\section{4) 0 ATIVISMO TRANSNACIONAL EM AÇÃO: A ATUAÇÃo DA ANISTIA INTERNACIONAL}

A história de ligação da atuação da ONG Anistia Internacional com a pauta dos povos indígenas se dá em um contexto posterior à realização da Conferência de Viena, organizada em 1993, quando essa ONG passa a atuar de forma mais intensa no cenário internacional devido ao seu reconhecimento pela ONU, a atenção que os Estados passam a ter à sua atuação e pela própria ampliação de seu mandato. Apesar disto, tal interação veio se aprimorando ao longo dos anos, como pôde ser observado já na II Conferência Mundial sobre o Meio Ambiente, a Rio 92, visto que nesta ocasião houve uma importante participação dos povos indígenas nas discussões realizadas dentro e fora do encontro dos chefes de Estado na ocasião reunidos (ALVES, 2001).

0 formato organizacional da Anistia Internacional, com seus escritórios espalhados em mais de 150 países, contribui para a criação de uma forte rede de informações, o que possibilita a ampliação de suas campanhas nacionais em temas de agenda internacional. Neste sentido, quando um escritório da Anistia Internacional assume uma campanha, esta se torna parte de todo o corpo das campanhas produzidas pela $\mathrm{AI}$, permitindo que as temáticas nacionais sejam exploradas e reivindicadas em outros espaços. Tal ação é a que permite e produz o shaming internacional, mencionado anteriormente. Ou seja, criam-se campanhas de caráter internacional que, forçam os Estados a reconhecerem seu comportamento, através da pressão pública internacional, exposta no cenário internacional e contraposta aos tratados internacionais assinados e ratificados pelos Estados, buscando alterar o comportamento violador (BAEHR, 2009). 
Em 2009, diante do cenário de luta constante e depois de uma série de encontros com a comunidade, a ONG Anistia Internacional, em conjunto com a comunidade Sawhoyamaxa, lançou uma campanha a fim de pressionar a restituição de suas terras, articulando grupos e ONGs nacionais e internacionais.

A campanha, organizada pelo escritório da Anistia Internacional Paraguai, contou com o apoio e adesão dos outros escritórios da AI distribuídos pelo mundo ${ }^{13}$, fundamentando-se no reconhecimento de tal comunidade e sua demanda, conforme figura abaixo:

Figura 1. Cartaz da campanha pela comunidade Sawhoyamaxa.

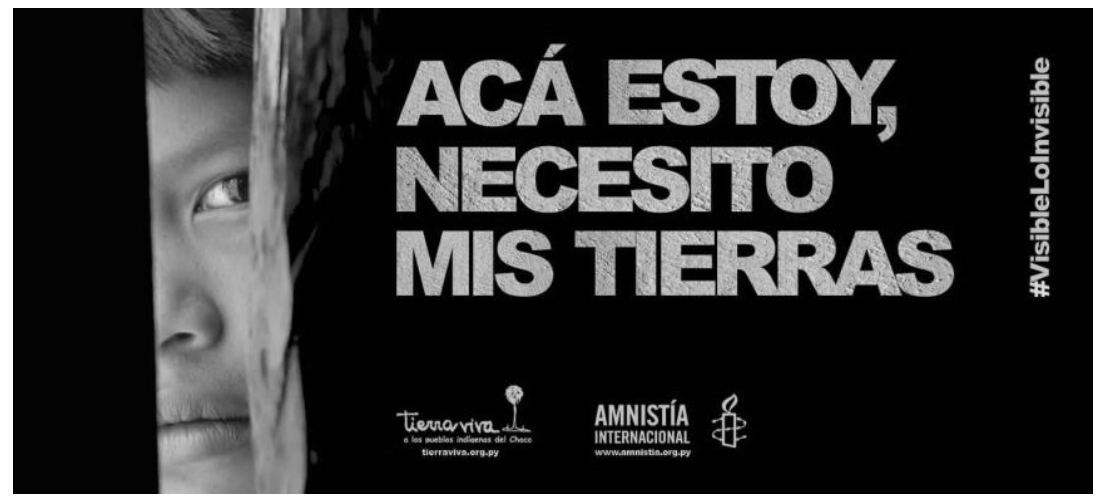

Fonte: http://amnesty.org.py/directores-de-amnistia-internacional-exigen-al-congreso-nacional-larestitucion-de-tierras-ancestrales-de-indigenas/

Além da produção de documentos e relatórios, como o intitulado "Estamos reclamando sólo lo que es nuestro"14 sobre a situação dos povos indígenas em território paraguaio, a Anistia Internacional organizou eventos e também conseguiu a adesão de importantes figuras nacionais e internacionais, procurando despertar a opinião pública. Este é o caso do apoio, durante toda a campanha, do vocalista do grupo musical portoriquenho Calle 13, que passou a pressionar e a levar aos seus concertos a temática do restabelecimento das terras dessa comunidade e a questão do descumprimento da decisão já tomada pela CIDH.

${ }^{13}$ É possível, por exemplo, encontrar com certo destaque a campanha e petição organizada pela Anistia na página dos escritórios desta na Holanda e Inglaterra.

${ }^{14} \mathrm{O}$ relatório está disponível para download em: < http://amnistiainternacional.org/publicaciones/73paraguay-estamos-reclamando-solo-lo-que-es-nuestro-pueblos-indigenas-de-paraguay-comunidadesyakye-axa-y-sawhoyamaxa.html>. 
Figura 2. Residente, vocalista do grupo musical Calle 13.

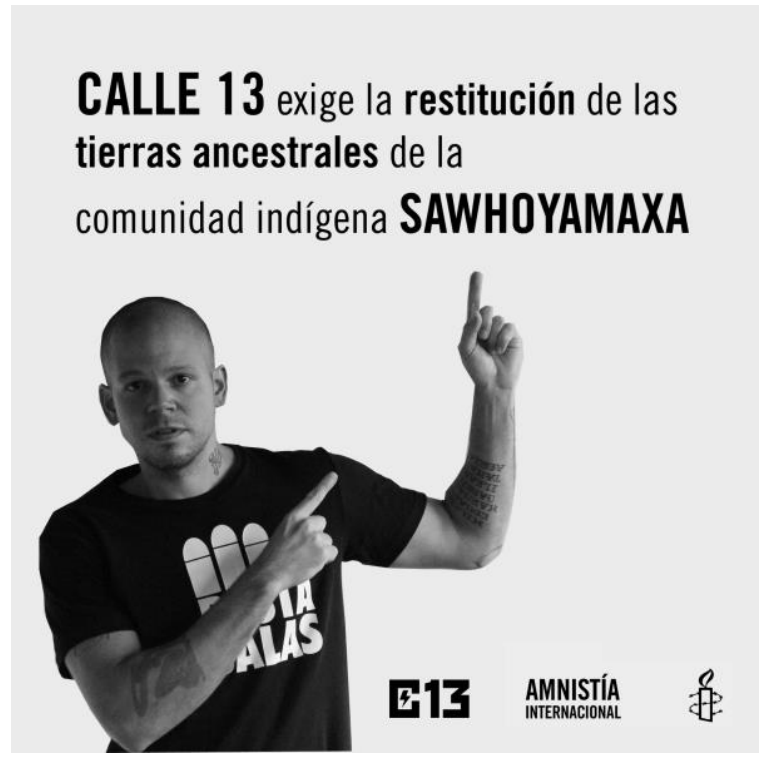

Fonte: http://amnesty.org.py/calle-13-exige-la-restitucion-de-las-tierras-ancestrales-de-los-sawhoyamaxa/

Assim, após 20 anos de mobilização, no dia 11 de junho de 2014, depois de cinco anos do início da campanha da Anistia Internacional Paraguai, realizou-se um ato que contou com uma grande participação de defensores da comunidade em frente ao prédio no qual se daria a decisão sobre a restituição das terras ancestrais da comunidade Sawhoyamaxa. Neste dia, finalmente, o presidente paraguaio, Horácio Cartes, assinou um documento que permitiu o retorno total dos membros da comunidade às suas terras ancestrais.

Diferente, entretanto é o caso da comunidade Apika'y. Em 2012, a Anistia Internacional realizou uma série de estudos, antes da organização de sua campanha, que permitiu a produção de um extenso relatório intitulado "Sabemos dos nossos direitos e vamos batalhar por eles"15. Nesse documento ficava evidente a morosidade em reconhecer o direito sobre suas terras ancestrais e a necessidade de mobilização, como podemos observar na figura abaixo:

Figura 3. Shalil Shety (Diretor da Anistia Internacional) e Atila Roque (Diretor da Seção da Anistia Internacional no Brasil) caminham junto aos povos indígenas, em visita às comunidades indígenas em Dourados- MS.

150 relatório está disponível em: < https://anistia.org.br/wp-content/uploads/2014/07/Guarani2011.pdf>. 


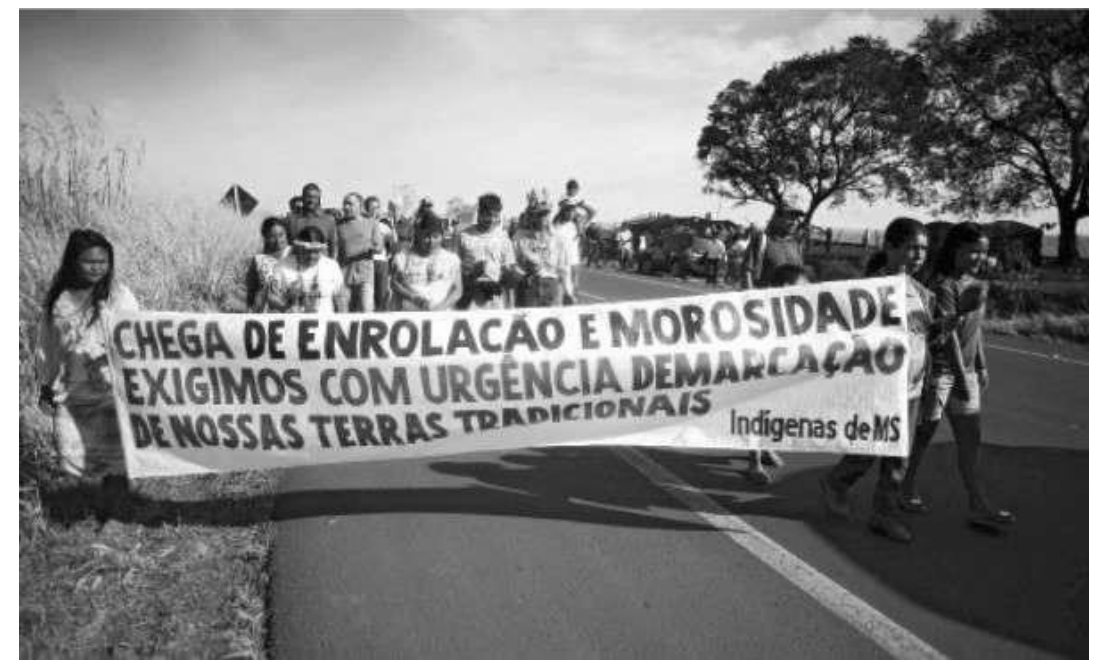

Fonte: https://anistia.org.br/noticias/direitos-dos-povos-indigenas-estao-sendo-massacrados-nas-americas/

Após a realização de conversas e encontros, o caso da comunidade Apika'y foi adotado pelo escritório da Anistia Internacional Brasil como um dos casos da Maratona de Cartas da Anistia Internacional: Escreva por direitos (2013), campanha mundialmente organizada. É importante mencionar que a visibilidade que a Anistia Internacional fornece a esses casos é propriamente a fonte geradora de pressão. Esta campanha foi o primeiro passo dado pela Anistia Internacional Brasil, no sentido de influenciar a ação do Estado diante da situação dessa comunidade de povos indígenas, como podemos visualizar abaixo:

Figura 4. Campanha organizada pela Anistia Internacional Brasil.

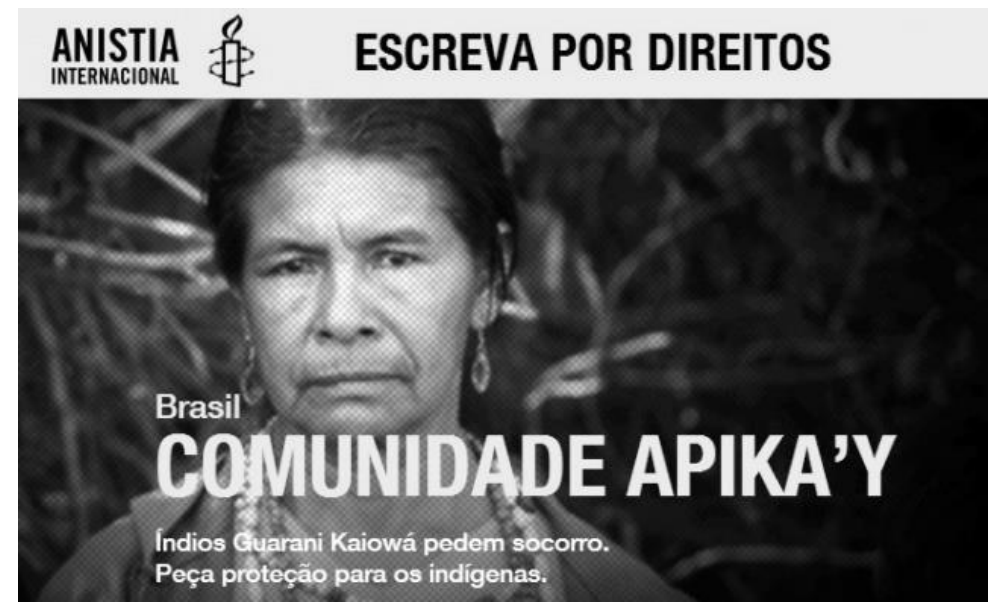

Fonte: https://anistia.org.br/entre-em-acao/carta/comunidade-apikay/ 
Dentre as ferramentas utilizadas pela ONG está a produção de um vídeo, legendado em diversas línguas, o qual apresenta a história de descaso do governo brasileiro e a situação enfrentada por esta comunidade. 16

Apesar da mobilização da comunidade Apika'y e da Anistia Internacional, tal caso ainda não foi solucionado. No Estado, apesar dos conflitos constantes entre fazendeiros e indígenas, o processo de demarcação de terras indígenas encontra-se paralisado.

\section{CONSIDERAÇÕES FINAIS}

Este trabalho procurou discutir o ativismo transnacional, considerando a atuação da Anistia Internacional nos casos relativos a comunidades tradicionais de Paraguai e Brasil.

Para tanto, procurou discutir o surgimento do ativismo transnacional e suas redes como um dos elementos importantes do cenário internacional contemporâneo, apontando a emergência de inúmeras redes transnacionais que contribuíram para o aprimoramento do ordenamento jurídico internacional e a publicização de demandas de grupos marginalizados.

No caso da comunidade Sawhoyamaxa (Paraguai), procuramos demonstrar que, apesar do ordenamento jurídico nacional e internacional e da mobilização da comunidade, a atuação da Anistia Internacional e a campanha (nacional e internacional) por ela desenvolvida, conseguiu pressionar e sensibilizar o poder público que, finalmente, respondeu a demanda da comunidade. Certamente a campanha não foi o único fator responsável por tal desenlace, mas permitiu uma maior visibilidade e relevância ao demonstrar a necessidade do governo paraguaio de se submeter às petições internacionais.

No caso da Apika'y (Brasil) podemos observar que, apesar da mobilização e campanha da Anistia Internacional, tal demanda ainda está longe de ser atendida pelo estado brasileiro. Isto pode ser resultado tanto dos limites da campanha e da influência desta no Estado brasileiro, como da força (econômica e política) de grupos contrários ao

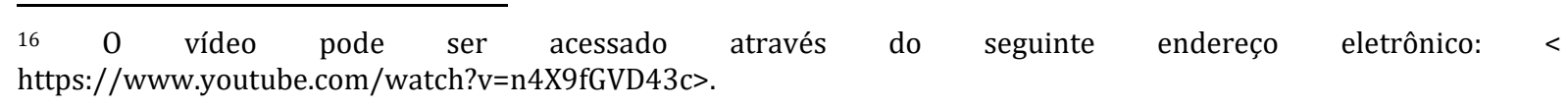


processo de demarcação de terras no país. De qualquer forma, tal campanha demonstra como o ativismo transnacional pode ser importante para a efetivação de direitos em comunidades tradicionais e marginalizadas, embora a organização e mobilização local continuem fundamentais.

Desta forma, a prática do ativismo transnacional entre comunidades indígenas é importante e interessante, pois conduz ao debate sobre seus direitos e a garantia de espaços nos fóruns internacionais e, ao mesmo tempo, permite uma atuação mais abrangente e globalizada de tais demandas. Entende-se, portanto, que essa atuação conjunta na organização de ativismo transnacional posiciona-se dentro dos aspectos da nossa atual sociedade e, apesar de importante, precisa superar alguns riscos. 0 principal deles é o da manutenção da autonomia das demandas locais e, por consequência, da necessidade de evitar a cooptação ou a utilização destas comunidades para outros fins e valores. Em suma, no limiar deste século, o ativismo transnacional se transformou numa importante estratégia para as demandas ignoradas, há séculos, pelas elites tradicionais.

\section{BIBLIOGRAFIA}

AHMED, S.; POTTER, D, M. NGOs in International Politics. United States: Kumarian Press, 2006.

AMNISTÍA INTERNACIONAL. Estamos reclamando sólo lo que es nuestro: pueblos indígenas de Paraguay- Comunidades Yanke Axa y Sawhoyamaxa. 2009. Disponível em:< http://amnistiainternacional.org/publicaciones/73-paraguay-estamosreclamando-solo-lo-que-es-nuestro-pueblos-indigenas-de-paraguay-comunidadesyakye-axa-y-sawhoyamaxa.html >. Acesso em: 13/07/2015.

AMNÍSTIA INTERNACIONAL. Hacer visible lo invisible. Amnistía Internacional. 2013. Disponível em: < http://www.amnesty.org.py/hacer-visible-loinvisible/apoya.html>. Acesso em 17/07/2016.

ANISTIA INTERNACIONAL. Sabemos dos nossos direitos e vamos batalhar por eles: direitos Indígenas no Brasil- Os Guarani-Kaiowá. 2010. Disponível em:< https://anistia.org.br/wp-content/uploads/2014/07/Guarani-2011.pdf.>. Acesso em: 13/07/2015.

ANISTIA INTERNACIONAL. Governos das Américas colocam o lucro à frente dos direitos dos povos indígenas. 2012. Disponível em: < https://anistia.org.br/noticias/governos-das-americas-colocam-o-lucro-frente-dosdireitos-dos-povos-indigenas/>. Acesso em 18/07/2016.

ANISTIA INTERNACIONAL. Paraguai: A decisão do Senado abre possibilidade de uma nova vida para os Sawhoyamaxa. 2014. Disponível em: < 
https://anistia.org.br/noticias/paraguai-decisao-senado-abre-possibilidade-deuma-nova-vida-para-os-sawhoyamaxa/>. Acessado em 18/07/2016.

ANISTIA INTERNACIONAL. Paraguai sanciona lei que devolve terra ancestral de comunidade indígena após 20 anos de luta. 2014. Disponível em: < https://anistia.org.br/noticias/paraguai-sanciona-lei-que-devolve-terra-ancestralde-comunidade-indigena-apos-20-anos-de-luta/>. Acessado em 18/07/2016.

ALVES, José Augusto Lindgren. Relações Internacionais e temas sociais: a década das conferências. Brasília: IBRI, 2001.

ARAUJO, Ana Valéria [Org]. Povos Indígenas e a Lei dos "Brancos": o direito à diferença. Brasília: MEC/UNESCO, Série Vias dos Saberes, 2006.

AZEVEDO et al. Guarani Retã. Povos Guarani na fronteira Argentina, Brasil e Paraguai. 2008 Disponível em: http://guarani.roguata.com/sites/default/files/guarani_reta_2008_caderno_em_po rt_0.pdf. Acesso em: 20/04/2015.

BOVO, Cassiano R. Martines. Anistia Internacional: roteiros da cidadania-em-construção. São Paulo: Annablume, 2002.

CONSTITUIÇÃO DA REPÚBLICA FEDERATIVA DO BRASIL. 1989.

CONSTITUICION DE LA REPUBLICA DEL PARAGUAY. 1992.

FINNEMORE, M; SIKKINK, K. International norm dynamics and political change. International Organization, 54 (4): 887-917, 1998.

KECK, M.; SIKKINK, Kathryn. Activists beyond borders. New York: Cornell University, 1998.

LINERA, A. G. A Potência Plebéia: ação coletiva e identidades indígenas, operárias e populares na Bolívia. São Paulo: Boitempo, 2010.

LITTLE, P. E. Territórios Sociais e povos tradicionais no Brasil: Por uma antropologia da territorialidade. Brasília, Série Antropologia, 332: 2-31, 2002.

PITTS, N. Mesmo sob ameaças de pistoleiros, indígenas Guarani Kaiowá vão permanecer em seu território. 2012. Disponível em: < http://www.adital.com.br/site/noticia_imp.asp?lang=PT\&img=N\&cod=69627>. Acessado em 18/07/2016.

POLANYI, Karl. A grande transformação. Rio de Janeiro: Editora Campus, 1980.

Della PORTA, Donatella; TARROW, Sidney. Transnational Protest and Global Activism: People, Passions, and Power. New York: Rowman \& Littlefield Publishers, 2004.

QUIJANO, Aníbal. Modernidad, identidad y utopia em América Latina. Lima: Sociedade e Política Ediciones, 1988.

SANTOS, Boaventura de Sousa [Org]. Reconhecer para Libertar: os caminhos do cosmopolitismo multicultural. Rio de Janeiro: Civilização Brasileira, 2010.

SEGATO, Rita Laura. Antropologia e direitos humanos: alteridade e ética no movimento de expansão dos direitos universais. Mana, 12 (1): 207-236, 2006. 
SIKKINK, K. The Justice Cascade: How Human Rights Prosecutions Are Changing World Politics. WW Norton \& Company, 2011.

TERRITORIO INDIGENA Y GOBERNANZA. Comunidad Indígena Sawhoyamaxa vs. Paraguay. $2006 . \quad$ Disponível em: http://www.territorioindigenaygobernanza.com/sawhoyamaxa.html. Acessado em 18/07/2016.

THE GUARDIAN. Paraguay's Supreme Court issues 'historic' land ruling. 2014. Disponível em: < https://www.theguardian.com/environment/andes-to-theamazon/2014/oct/07/paraguay-supreme-court-historic-land-ruling>. Acessado em $18 / 07 / 2016$.

VILLA, Rafael A. Formas de influência das ONG na política internacional contemporânea. Revista de Sociologia e Política, Curitiba, 12:21-33, 1999. 